\title{
Determination Of The Factors Affecting The Food Security Status Of Households In Bophelong, South Africa \\ TJ Sekhampu, North-West University, South Africa
}

\begin{abstract}
This study investigates the food security status of households in the township of Bophelong, South Africa. The results are based on a household survey using questionnaires. A Logistic regression model was estimated based on this data with the household food security status (that is food secure and insecure) as the dependent variable and a set of demographic variables as explanatory variables. It was found that about 26 percent of the sampled households are food secure. Further analysis identified household income, household size, marital status, employment status, age and gender of the household head as important determinants of food security. While other variables of importance positively influenced food security, household size and the marital status of the household head were negatively associated with household food security. The educational attainment of the household head was not important in explaining the variation in household food security status. Information provided by this study can be used as a reference source for policy decisions regarding household food security in South Africa.
\end{abstract}

Keywords: Food Security; Determinants; Regression; Township; South Africa

\section{INTRODUCTION}

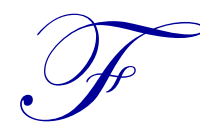

ood security is a broad concept that includes issues related to the nature, quality, food access and security of the food supply (Iram \& Butt, 2004). The problem of food security includes people's risks of not having access to the required food. Food insecurity is increasing in the world where 925 million people are undernourished. Approximately 900 million of these are living in developing countries (FA0, 2010). The status of food insecurity and hunger cannot be captured by any single indicator. The United States Department of Agriculture (USDA) has developed a food security measurement, including the following types of household conditions, events, behaviors, and subjective reactions (USDA, 2000):

- $\quad$ Anxiety that the household food budget or food supply may be insufficient to meet basic needs;

- $\quad$ The experience of running out of food, without money to obtain more;

- $\quad$ Perceptions by the respondent that the food eaten by household members was inadequate in quality or quantity;

- $\quad$ Adjustments to normal food use, consuming fewer or cheaper foods than usual;

- Instances of reduced food intake by adults in the household or consequences of reduced intake, such as the physical sensation of hunger or loss of weight; and

- Instances of reduced food intake or consequences of reduced intake for children in the household.

All of these food security questions have two characteristics in common. Each question aims to assure that the reported behavior or condition occurred because of household financial limitations by including phrases such as "because we couldn't afford that" or "because there wasn't enough money for food" (USDA, 2000: 9). PinstrupAndersen (2009: 1) argues that household food security may not ensure food security for all its members. Firstly, having the financial means to acquire enough food may not be converted into actual food acquisition. Household preferences may not prioritize food acquisition over the acquisition of other goods and services, such as school fees and housing. Secondly, the intra-household allocation of the food may not be based on the needs of each individual 
member. The multidimensional nature of food security has rendered the measurement of food security difficult (Abuelhaj, 2007). Accounting for the complexity in measuring such a construct, analysts have turned to measure distinct facets of food security rather than the whole. These could be limited to measuring distinct aspects, such as quantity or quality of consumed food or the psychological, social and cultural aspects of food insecurity (Elijah, 2010: 1). Monitoring food security can help to identify and understand this basic aspect of well-being of the population and to identify population subgroups or regions with unusually severe conditions. Food insecurity results in substantial productivity losses because of reduced work performance. Food security and adequate nutrition are seen as beneficial inputs to economic development. Poor nutrition and health in early childhood can have long-term consequences that affect the child's progress in school (Von Braun, 1992: 23).

Food security is part of the section 27 Constitutional rights in South Africa. The Constitution states that every citizen has the right to have access to sufficient food and water. The Reconstruction and Development Programme (RDP) in 1994 identified food security as a priority policy objective. As a result, the government reprioritized public spending to focus on improving the food security conditions of historically disadvantaged people. The policy resulted into increased spending in social programs by all spheres of government, such as school feeding schemes, child support grants, free health services for children between 0-6 years, for pregnant and lactating women, pension funds for the elderly, the working for water programme, and community public works programs (ANC, 1994). The efforts to address food security culminated in the compilation of the integrated food security strategy. The vision of the Integrated Food Security Strategy is to attain universal physical, social and economic access to sufficient, safe and nutritious food by all South Africans at all times to meet their dietary and food preferences for an active and healthy life (Department of Agriculture, 2002). At the national level, South Africa is food secure as it adequately produces its main staple foods and has the means to imports what it needs to meet its food requirements. National food security indicators reveal that South Africa has been meeting its food needs of its growing population at a national level in the past. Household level analysis reveals a different picture. The South African reality is that approximately fourteen million South Africans are vulnerable to food insecurity. Among these, women, children and the elderly are particularly vulnerable. Further analysis shows food insecurity is highest among the African population, but also affects many Coloured households. A study by Jacobs (2009) concluded that approximately $80 \%$ of households could not afford to buy a basic nutritional basket of food costing an average of $\mathrm{R}$ 262 per person per month (at 2005 prices).

It is well documented that South Africa's historical circumstances have shaped the present configuration of poverty and opportunities along racial lines. Disadvantaged groups were systematically left with relatively little in the way of land and other resources and were not afforded education of a quality comparable to that of whites. Food consumption is an important issue in South Africa, given its relation to poverty and deprivation. With the pressing need to increase food security, understanding the determinants of demand for food has become a vital task. A formerly blacks-only township in South Africa provides an ample case study. Von Braun et al. (2009) notes that household food security monitoring requires disaggregated consumption information at the household level, based on surveys. They further argue that socio-economic, demographic and nutritional variables can complement programs that monitor changes in household food security. To understand household food security status, it is necessary to investigate how the resources of a household determine its access to food (Altman et al., 2009:7). Several studies have been undertaken in other parts of the world in an attempt to measure food security. Arene (2008) used logistic regression to analyze the food security status of households in Nigeria. A food secure household was one whose per capita monthly food expenditure was at least two-thirds of the mean per capita monthly food expenditure of the sample. The study found household income and the age of the head of the household as important determinants of food security. A study by Bashir et al. (2012) in Pakistan concluded that household's monthly income and household head's education levels were positively impacting household food security. On the other hand, the household head's age and family size were negatively associated with household food security. The food security status of the landless households was measured by calculating their per capita calorie intake using a 7-day recall method. The calculated calories were converted into per capita intakes after adjusting to adult equivalent units to nullify the impacts of age and gender differences.

For this study, food security is defined as the ability of a household to secure enough food to ensure adequate intake for all its members. The South African National Department of Agriculture's proxy food poverty line was used as a measure of the food security status of a household. A household's total food expenditure was 
compared to the proxy food expenditure poverty line of R260 per adult per month. A random sample of households was surveyed in a township called Bophelong (about 70km south of Johannesburg).

\section{RESEARCH METHODOLOGY}

\section{Study Area}

The geographical area covered by the study entails the area called Bophelong, located near Vanderbijlpark in the southern part of Gauteng. Bophelong was established in 1955. The area belongs to the Emfuleni Municipality in the southern part of the Gauteng Province of South Africa. In the late 1990s, the area was extended with the addition of 10,000 new so-called low-cost houses. Most of the people who settled in these new houses were poor and previously could not afford a house. The population in Bophelong is approximately 37,779 and the number of households is estimated to stand at 12,352. The average household size in Bophelong, calculated from Statistics SA data (2007), is three persons per household. The average household size for Emfuleni, as a whole, is 3.52 individuals. Bophelong is approximately 9 square kilometers in size. Its residents are mainly employed as domestic or industrial workers in the nearby town of Vanderbijlpark. Previous studies have found seemingly high poverty levels in the area, where 67\% of the households were found to be poor in 2003 (Slabbert, 2003). A study by Sekhampu (2004) reported that $62 \%$ of the households were poor using income measures of poverty. A similar study by Slabbert (2009) revealed increasing levels of poverty where $69 \%$ of the sampled population in Bophelong was found to be poor. The data for this study were collected during March 2012. A total of 600 questionnaires were randomly administered in the area through face-to-face interviews. Data from 585 households were analyzed to serve the purpose of this study. The survey questionnaire was tested before its distribution and necessary adjustments were made. Data were collected by interviewing the household head (the major decision-maker). The questionnaire included information on demographics, respondents' income and expenditure patterns, and their general view about their socio-economic status. Data were collected on monthly household expenditure on food and non-food items. Several statistical methods were used to analyze the data using Statistical Package for the Social Sciences (SPSS). Data were analyzed using food security status estimation and logistic regression analysis.

\section{Data Analysis}

The data were analyzed in two stages. Stage one calculates the food security status of each household and stage two is an analysis of the determinants of food security. The Department of Agriculture's recommended food security poverty line was used to aggregate households into food secure and insecure. Each household's total monthly food expenditure was compared with their specific food poverty line based on household size, gender and age distribution of the household members. The South African food security policy recommends an adult individual daily energy consumption of 2,650 kilojoules. The policy sets an adult equivalent food poverty line of R260 per individual expenditure for food every month to serve as a proxy indicator for food security. This amount is said to cover 70\% of the basic nutrition basket (Department of Agriculture, Forestry \& Fisheries, 2012: 9). Because individuals vary greatly in their nutritional needs, the food poverty line was equalized using the recommended energy allowances based on the gender and age distribution of the household members. Table 1 shows the equivalence scale for the different age groups and gender as recommended by the National Department of Health in South Africa. Although adjustment factors are available to account for pregnancy and lactation, as well as for HIV status, these have not been included in the calculation.

Table 1: Adult Equivalence Of The Food Poverty Line

\begin{tabular}{|l|c|c|}
\hline \multicolumn{1}{|c|}{ Age Category } & Male & Female \\
\hline$<1$ & 0.19 & 1.19 \\
\hline $1-3$ & 0.50 & 0.50 \\
\hline $4-6$ & 0.75 & 0.75 \\
\hline $7-9$ & 0.88 & 0.88 \\
\hline $10-12$ & 1.01 & 0.89 \\
\hline $13-15$ & 1.14 & 1.05 \\
\hline $16-17$ & 1.38 & 1.06 \\
\hline $18-29$ & 1.37 & 1 \\
\hline $30-60$ & 1.34 & 1 \\
\hline 60 & 1.11 & 0.9 \\
\hline
\end{tabular}

Source: (Tshitaudzi, 2007) 


\section{Regression Model}

A binary logistic regression model was used to determine the effects of some socio-economic and demographic characteristics of the households on their food security status. The binary logistic specification is suited to models where the endogenous variable is dichotomous, which, in this case, are the households who are food secure and those who are food insecure. Food security status was measured using a bid value of one or zero, where one represents food secure and zero represents food insecure. The logistic regression then provides a model of observing the probability of a household becoming food secure or food insecure. The selection of variables likely to influence household food security relies on previous studies by Stewart et al. (2004), McCracken and Brandt (1987), and Redman (1980). The regression model was estimated as follows:

$Y=\beta_{0}+\beta_{1} x_{1}+\beta_{2} x_{2}+\beta_{3} x_{3} \ldots \ell_{t}$

where $\mathrm{Y}$ is the food security status ( 1 if household is food secure and 0 if household is food insecure), while $\mathrm{X}_{\mathrm{t}}$ is vector of explanatory variables, and $\beta_{0}$ is the vector of unknown parameters (Intercept), and $\ell_{\mathrm{t}}$ is the error term. The following socio-demographic characteristics are therefore hypothesized to influence total household food security: $\beta_{1}$ total monthly household income recorded in Rands, $\beta_{2}$ household size, $\beta_{3}$ education attainment of the household head, $\beta_{4}$ gender, $\beta_{5}$ age, $\beta_{6}$ marital status, and $\beta_{7}$ employment status of household head.

\section{EMPIRICAL FINDINGS}

\section{The Demographic Characteristics Of The Respondents}

The sample data were based on responses from the head of the household. The results showed that the youngest head of household was 18 years and the oldest was 90 years old. The number of persons per household varied from 1 to 13 members. The average household had four members. There were greater variations in household income, with the lowest household income recorded at R30 per month and the highest at R18,000. Household income is the total income earned/received by the various household members. Furthermore, $49.4 \%$ of households were headed by females (G_Head). The average number of years of schooling of the respondents (Educ_Head) was 6.21 years, which equates to primary school education. A small percentage $(1.6 \%)$ of household heads had a postschool qualification and $12.5 \%$ of the respondents had no formal education. An analysis of the marital status of the respondents shows that $47.2 \%$ were married. Regarding the employment status of the respondents, $58.1 \%$ were not employed. The lowest monthly food expenditure was R90 and the highest at R3,686 per month. The monthly average food expenditure was recorded at R748.93.

\section{An Analysis Of The Food Security Status Of The Households}

For the purpose of this study, a food security poverty line was individually calculated for each household and the household's food consumption was compared to its own individual poverty line. These calculations allow one not to only account for the number of food secure households, but also the extent of the food insecurity. The results of the survey showed that $26 \%$ of sampled households were food secure. These are households whose total food expenditure was greater than their respective food poverty line.

\section{Factors Affecting Household Food Security}

The results of the regression analysis on the factors that affect household food security are shown in Table 2. The results of the survey show that household income (HH_Income), household size (HH_Size), age (Age_Head), gender (G_Head), the employment (ES_Head) and marital status (MS_Head) of the head of the household are important predictors of household food security. These variables were found to be statistically significant predictors of household security. Specifically, household size (HH_Size; $\mathrm{p}=0.000)$ and the marital status of the head of the household (MS_Head; $\mathrm{p}=0.018$ ) had a negative influence on the food security status of a household. Other variables of significance (household income- $\mathrm{HH} \_$Income; $\mathrm{p}=0.000$ ), the age- Age_Head; $\mathrm{p}=0.011$ ) and gender of the household head (G_Head; $\mathrm{p}=0.001$ ) were found to exert a positive impact on food security. The educational 
attainment of the head of the household (Educ_Head) was not important in explaining the variations in household food security status. The statistical non-significance of this coefficient suggests that this variable is not important with regard to explaining the food security status of the sampled households.

Table 2: The Socio-Economic Factors Affecting Household Food Security

\begin{tabular}{|c|c|c|c|c|c|c|c|}
\hline & \multirow{2}{*}{ B } & \multirow{2}{*}{ S.E. } & \multirow{2}{*}{ Wald } & \multirow{2}{*}{$\mathbf{p}$} & \multirow{2}{*}{ Odd Ratio } & \multicolumn{2}{|c|}{ 95\% C.I. for Odd Ratio } \\
\hline & & & & & & Lower & Upper \\
\hline HH_Income & .000 & .000 & 48.901 & .000 & 1.000 & 1.000 & 1.001 \\
\hline HH_Size & -.678 & .086 & 61.941 & .000 & .508 & .429 & .601 \\
\hline Age_Head & .022 & .009 & 6.525 & .011 & 1.022 & 1.005 & 1.040 \\
\hline G_Head & .841 & .242 & 12.111 & .001 & 2.319 & 1.444 & 3.725 \\
\hline ES'_Head & .456 & .272 & 2.812 & .094 & 1.578 & .926 & 2.690 \\
\hline Educ_Head & .042 & .030 & 1.979 & .159 & 1.043 & .984 & 1.106 \\
\hline MS_Head & -.571 & .241 & 5.621 & .018 & .565 & .353 & .906 \\
\hline Constant & -1.411 & .578 & 5.966 & .015 & .244 & & \\
\hline
\end{tabular}

To select a good model, a number of tools for model adequacy can be employed. The Hosmer-Lameshow goodness of fit statistic shows the possible deviation from the underlying fitted distribution, while the percentage of correct predictions made after fitting the model on the observed data is another way to assess its applicability. The model containing all explanatory variables was significant $\chi^{2}(5 \mathrm{~N}=585)=173.80 \mathrm{P}<0.001$, implying that the variation in food security status is due to the stated socio-economic and demographic characteristics of the sample. The model, as a whole, explained 25.7\% (Cox and Snell R Squared) and 37.6\% (Nagelkerke R Squared) of the variance in household food security status and correctly classified $82.6 \%$ of all cases.

\section{DISCUSSION AND CONCLUSION}

The results of the regression analysis on the factors influencing household food security status suggest that household income, household size, age, employment status, gender and the marital status of the head of the household are significant predictors of food security. Specifically, household income is positively associated with the food security status of a household. Household income is important as it determines how much can be spent on various needs of the household. The quantity and quality of a household's expenditure patterns are highly correlated with the purchasing power of the household. A household's monthly income consists of the total monetary receipts (income from salaries, help in kind, etc.) from all sources. These findings are consistent with similar studies on food security. Bashir et al. (2010) also found a positive impact of income on food security. Another study by Onianwa and Wheelock (2006) in the USA found a positive relationship between a household's food security status and household income.

Larger household sizes are associated with a negative food security status. Larger household sizes require increased food expenditure and competition for limited resources. It was expected that household size would significantly impact household food security. The negative parameter could be a result of an increase in the dependency ratio in larger households. The age of the household head was positively associated with food security. The coefficient for age $(\mathrm{B}=-.678)$ was positive and significant at $1 \%$. In a related study, Bashir et al. (2012) found that an increase of one year in the age of household head decreases the chances of a household to become food secure. A study by Omonoma \& Agoi (2007) in Nigeria found an inverse relationship between the age of household head and food security. The results of this study seem to augur with a study by Arene and Anyaeji (2010) who concluded that the increased age of the household head had a positive effect on food security status.

The gender of the household head had a positive impact on the food security status of the households. In particular, the female gender had a positive impact on household food security. Among the food insecure households, $50.9 \%$ of the household heads are male, while $49.1 \%$ are female. These 'percentages are in line with the food secure households where male-headed households constitute $50 \%$ of the respondents. The importance of the gender (female) of the head of the household in the food security status of a household might be due to the slightly smaller household size in households headed by females (3) compared to males (4). The marital status of the respondents was negatively associated with food security. The negative parameter $(B=-.571)$ indicates that with 
other variables constant, households where the head is married have a higher probability of being food insecure. This result needs to be contrasted with that of the gender of the household head. Female-headed households were found to have a higher probability of being food secure. Of the total sample, $47.2 \%$ of respondents were married. The employment status of the household head was also found to be a significant predictor of food security. The coefficient for age $(\mathrm{B}=.456)$ was positive and significant at $1 \%$. The problems to urban residents in achieving food security include unemployment, poor health and nutrition, scarcity of land, and high population density. Unemployment rate is considerably high in many urban areas. This calls for employment opportunities among urban residents in order to ensure food security. The educational attainment of the head of the household was not important in explaining the variations in household food security. This might be due to the high unemployment rate (58.1\%) among the respondents, resulting in lower returns for education in the market. As a result, education may not help much to improve the food security status of households.

The results of this study can provide useful information for policy-makers in efforts to improve urban household food security in South Africa. Food production at the household level needs to be encouraged in order to ensure increased opportunities of access to food. Improvements in income earning opportunities should also be made. Targeted programs to female-headed households need to be investigated as females bear the brunt of the food insecurity. It is worth noting that a major shortcoming of the methodology used in this study is that it asks whether a household's food expenditure represents a proxy for an adequate nutritional basket. Further research could compare results of various assessment tools and the coping strategies of vulnerable and food insecure households. Information provided through this study is at the household level and is meant to highlight trends among low income households in South Africa.

\section{AUTHOR INFORMATION}

Dr. TJ Sekhampu, Senior Lecturer in Economics at North-West University, South Africa. His principal research is on poverty and socio-economic studies. E-mail: joseph.sekhampu@nwu.ac.za

\section{REFERENCES}

1. Abuelhaj, T. (2007). Methodological concerns in the measurement of undernourishment, dietary diversity and household food insecurity. Retrieved Dec 1, 2012, from http://km.fao.org/fileadmin/user_upload/fsn/docs/fao tareq.pdf

2. Altman , M., Hart T, T., \& Jacobs, P. (2010). Household food security status in South Africa. Agrekon, 84(4), 345-361.

3. ANC (African National Congress). (1994). The Reconstruction and Development Programme . Johannesburg: ANC.

4. Arene, C., \& Anyaeji, C. (2010). Determinants of food security among households in Nsukka Metropolis of Enugu State, Nigeria. Pakistan Journal of Social Sciences, 30(1), 9-16.

5. Arene, C. (2008). Agricultural economics: a functional approach. Abuja: Prize Publishers.

6. Bashir, M., Naeem, M., \& Niazi, S. (2010). Rural and peri-urban food security: a case of district Faisalabad of Faisalabad of Pakistan. WASJ, 9(4), 403-41.

7. Bashir, M., Schilizzi, S., \& Pandit, R. (2012). The determinants of rural food security: the case of landless households of the Punjab, Pakistan. Crawley: aSchool of Agricultural and Resource Economics, The University of Western Australia.

8. Department of Agriculture. (2002). The Integrated Food Security Strategy of South Africa. Pretoria: Government Printer.

9. Department of Agriculture, Forestry and Fisheries. (2012). Food Security Policy of the Republic of South Africa. Pretoria: Government Printer.

10. Elijah, O. (2010). Classification of households into food security status in the North-Central Region of Nigeria: an application of Rasch Measurement Model. ARPN Journal of Agricultural and Biological Science, 5(3), 26-41.

11. FAO. (2010). The state of food insecurity in the world: addressing food insecurity in protracted crises. Rome: United Nations' Food and Agricultural Organisation. 
12. Iram, U., \& Butt, MS. (2004). Determinants of household food security: An empirical analysis for Pakistan. International Journal of Social Economics, 31(8): 753 - 766

13. Jacobs, P. (2009). Identifying targets for household food security in South Africa. Pretoria: Centre for Poverty, Employment and Growth, Human Science Research Council.

14. Malik, S. (1996). Determinants of rural poverty in Pakistan: a micro study. The Pakistan Development Review, 35(2), 171-187.

15. McCracken, V., \& Brandt, J. (1987). Household consumption of Food Away from Home: total expenditure and by type of food facility. American Journal of Agricultural Economics, 69(3), 274-284.

16. Omonoma , B., \& Agoi , G. (2007). An analysis of food security situation among Nigerian urban households: evidence from Lagos State, Nigeria. Journal of Central Europena Agriculture, 8(3), 307-406.

17. Onianwa, O., \& Wheelock, G. (2006). An analysis of the determinants of food insecurity with severe hunger in selected southern states. Southern Rural Sociology, 21, 80-96.

18. Pinstrup-Anderson, P. (2009). Food security: definition and measurement. Food Security, 5-7.

19. Sekhampu, T. (2004). An in-depth micro-economic analysis of the poor in Bophelong with specific reference to the activities they use to sustain themselves. M.Com Dissertation. Vanderbiljpark: North-West University.

20. Selvanathan, E., \& Selvanathan, S. (2006). Consumption patterns of food, tobacco and beverages: a cross country analysis. Applied Economics, 1567-1584.

21. Slabbert, T. (2003). Bophelong: a socio-economic \& environmental analysis. Vanderbijlpark: Vaal Research Group.

22. Slabbert, T. (2009). Bophelong: a socio-economic \& environmental analysis. Vanderbijlpark: Vaal Research Group.

23. Statistics South Africa. 2007. A discussion note: Constructing comparable household survey data for the analysis of poverty in South Africa (1995-2000). Pretoria: Government Printer.

24. Steward, H., Blisard, N., Byuyan, S., \& Nayga, R. (2004). The demand for Food from Home: full-service or fast food. United States: Economic Research Service, US Department of Agriculture.

25. Tshitaudzi, G. (2007). Nutritional requirements for individuals. Government Printer: Department of Health.

26. USDA. (2000). Guide to measuring household food security. Alexandria: Food and Nutrition Service, USDA.

27. Von Braun, J., Buis, H., Kumar, S., \& Pandya-Lorch, N. (1992). Improving food security of the poor: concept, policy and programs. Washington: International Food Policy Research Institute. 
NOTES 